\title{
MODAL ANALYSIS FOR REVISION OF A FEM MODEL OF A STEEL TRUSS BEAM
}

\author{
Michal Venglar*, Milan Sokol, Monika Marfoldi \\ Slovak University of Technology in Bratislava, Faculty of Civil Engineering, Department of Structural \\ Mechanics, Radlinskeho 11, 81005 Bratislava, Slovak Republic \\ * corresponding author: michal.venglar@stuba.sk
}

\begin{abstract}
The paper deals with a preparation of a complex FEM model for a local damage detection. The initial verified and validated three-dimensional FEM model of a steel truss bridge in laboratory is revised step-by-step to achieve the accurate model according to the experimental model. The emphasis is on modelling of the joints with 4 rivets and modelling of correct boundary conditions, as well as mass parameters and cross-section dimensions. A modal analysis of the structure is performed in FEM software. Many experimental measurements were made to correctly revise the FEM model. The calculated natural frequencies are compared with the measured ones. In addition, mode-shapes from the calculation are validated with the measured mode-shapes. The difference between the prepared FEM model and the measured specimen is small enough after a few steps of tuning. The verified, validated and revised numerical model can be used in future for a local damage detection.
\end{abstract}

KEYwords: Modal analysis, revision of FEM model, experimental measurements, rivet joint connection.

\section{INTRODUCTION}

Civil infrastructure like bridge structures deteriorate with time due to various reasons. The reasons are, e.g., fatigue failure, extreme events, etc. In addition, many of these structures worldwide are currently nearing the end of their proposed design life. This situation can result into a necessity of major rehabilitation. According to the 2017 Infrastructure Report Card [1] produced by the American Society of Civil Engineers (ASCE) almost 4 in 10 bridges are over 50 years and older. This means that bridge structures in the USA are 43 years old on average. Situation in Slovakia is almost the same. Because of mentioned state, structural health monitoring (SHM) and system identification of bridges is currently reaching popularity among research teams around the world [2]7]. Moreover, increasing safety demands of new-constructed bridges and buildings confirms the interest. The SHM of bridge structures can help to prevent from the stated situations. Therefore, this paper deals with one of the first parts of SHM (preparation of a FEM model of bridge specimen).

\section{LABORATORY SPECIMEN}

A steel truss bridge was scaled to approximately 1:15. The whole length of the specimen was $3.4 \mathrm{~m}$. The cross-section of the truss is closed (through truss) with a width of $0.435 \mathrm{~m}$ and a height of about $0.8 \mathrm{~m}$. The cross-section of upper and lower chords has been chosen as a square hollow section SHS $15 \times 1.5 \mathrm{~mm}$. Diagonals of the truss beam form a $63^{\circ}$ angle with the bottom and/or with the upper chords. The diagonals at the joints have the same cross-section as the chords (SHS $15 \times 1.5 \mathrm{~mm}$ ) that changes to a full round bar

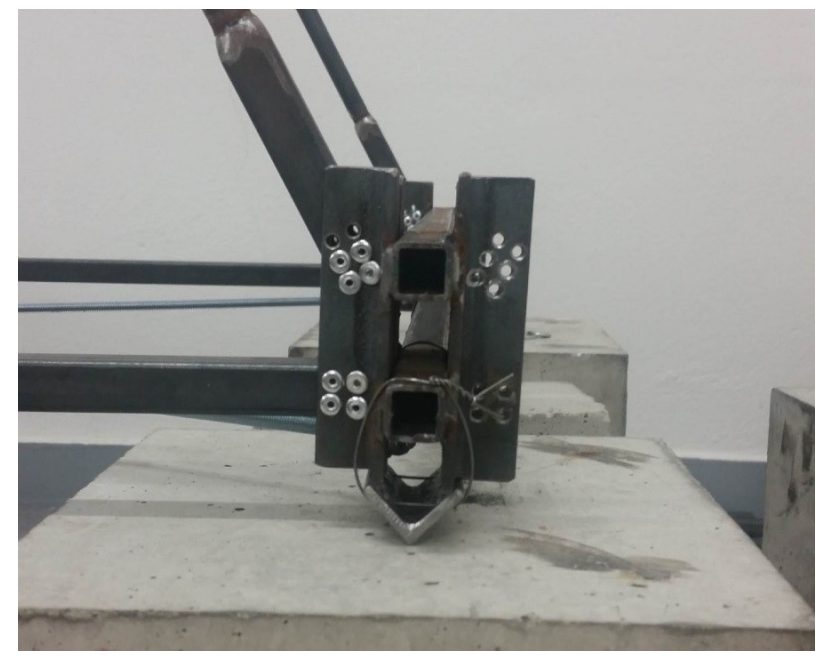

FiguRE 1. The boundary conditions.

with a radius of $12 \mathrm{~mm}$. Floor beams consists of two SHS $15 \times 1.5 \mathrm{~mm}$ bars which have been welded together. Rods with a diameter of $6 \mathrm{~mm}$ are used for top and bottom lateral bracing. Steel components included the following nominal properties: elastic modulus $200 \mathrm{GPa}$ and Poisson ratio equals to 0.3. The experimental model has also been weighed for comparison with the numerical model.

\section{Experimental Measurements}

The used boundary conditions of the experimental model were as a simply supported beam. The truss beam was supported at 4 places. You can see it in Figure 1

Accelerometers MMF KS901.100 were placed at 13 points. Magnetic mounting was used because of pos- 


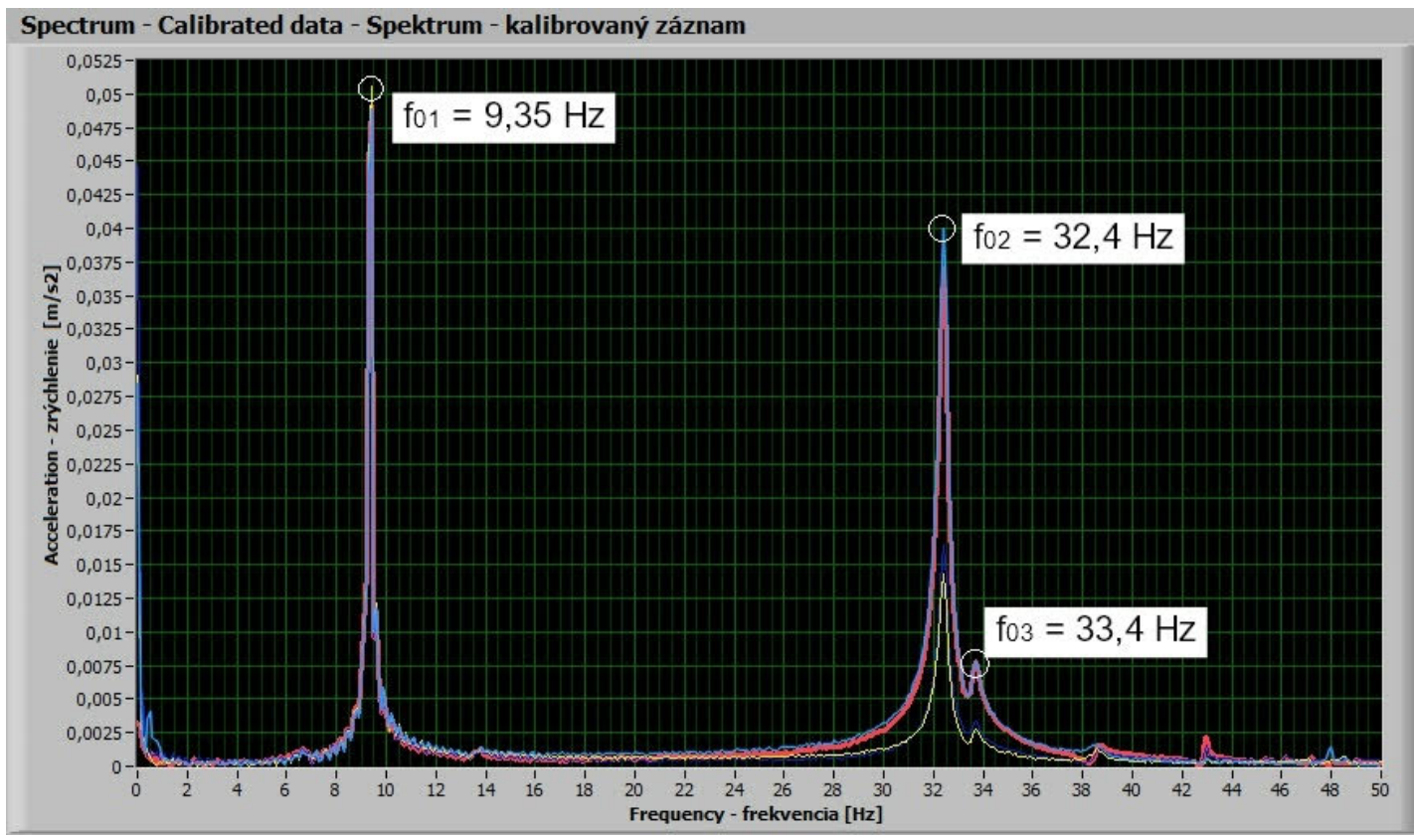

Figure 2. The natural frequencies from initial measurements.

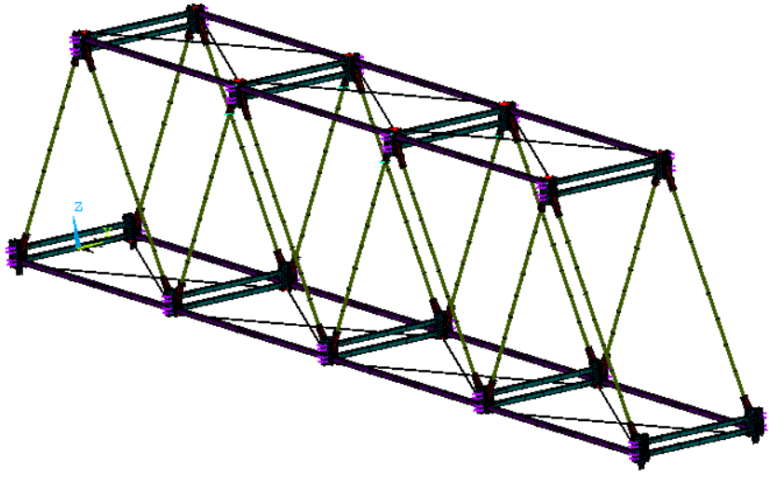

Figure 3. The numerical model.

sibility to change place of sensor [8] in accordance with investigated mode-shape. The air temperature reached approximately $20{ }^{\circ} \mathrm{C}$ during the measurements and it was measured because of possible influence on repeated dynamic measurements in the future. The first three natural frequencies from measurements are shown in Figure 2 Analysis of the measurement data was done in software National Instruments LabVIEW and ModalVIEW R2.

\section{MODEL REVISION}

In accordance with [9], the comparison of experimental outcomes and simulation outcomes was done. The simulation outcomes were prepared in the FEM code where the numerical model (Figure 3) was made from shell, beam elements and mass elements was also used for lumped mass. Firstly, the model was verified and validated. Then, the experimental outcomes were acquired in accordance with Section 3

As it was mentioned in Section 2 the weight of the laboratory specimen with accessories was compared

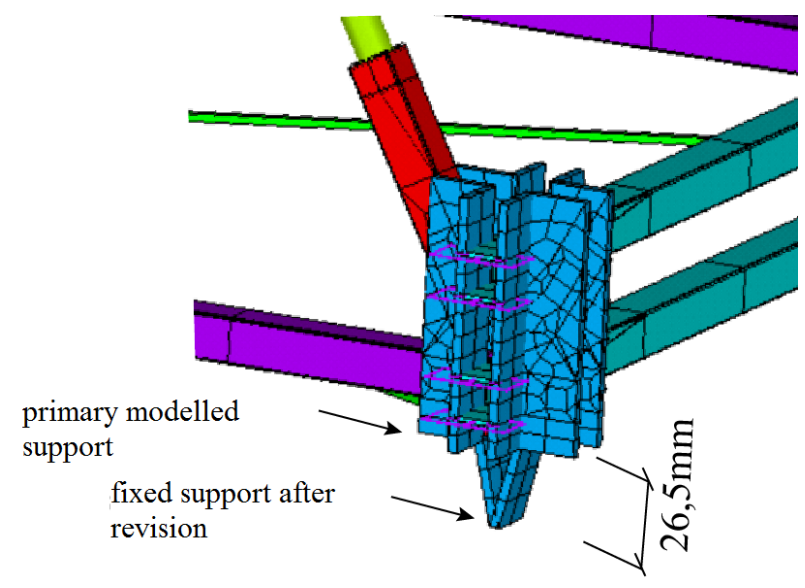

Figure 4. Revised boundary conditions.

with the numerical model. The numerical model has also considered the weight of the used accelerometers MMF KS901.100. At the beginning, the whole mass did not correspond to the mass of numerical model. Then, cross-sectional dimensions and mass of individual elements of the system were carefully measured. The occurred difficulty during the process of validation was different thickness of individual cross-sections. Finally, the whole mass was adjusted to weight of the experimental specimen.

Another difficulty which occurred during the validation and following revision of the model represents the boundary conditions. After many simulations, the boundary conditions were achieved by modelling L-profiles (Figure 4) with the same length placed in four corners of the specimen.

Modelling of the hinge joints by using rivets (Figure 5 was done as the final step. The rivets were modelled using a single-axis element that allows to specify 


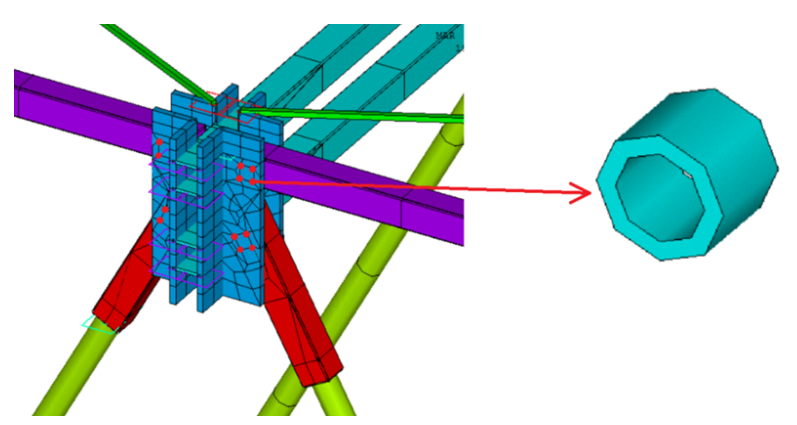

FiguRE 5. Rivets in the numerical model.
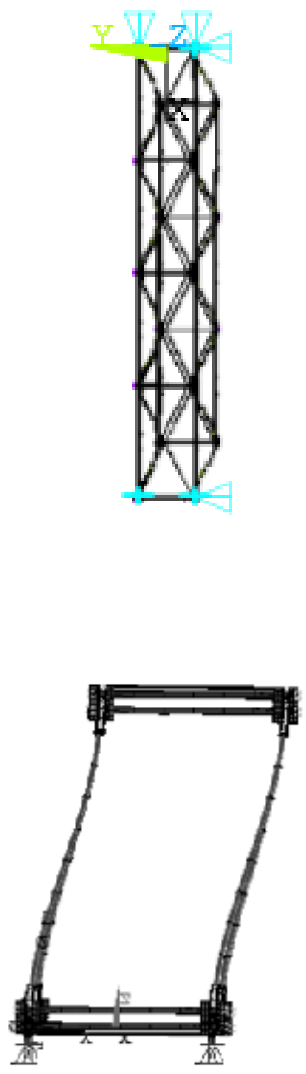

Figure 6. The first calculated mode-shape: view (top) and cross-section (bottom).

the outer diameter and thickness of the cross-sectional area. The thickness of the used rivets influenced each of the global natural frequency as well as frequencies of local vibrations of diagonal members. The most suitable value of the thickness was equal to $0.45 \mathrm{~mm}$.

\section{Results of REVision}

After verification, validation and revision of the numerical model, final modal analysis was done. The first natural frequency represents $9.37 \mathrm{~Hz}$. When the structure is deformed in its the first mode-shape, the entire upper part of the structure with diagonals moved in the direction of the $\mathrm{Y}$ axis, as you can see in Figure 6 .

For a comparison with the first calculated modeshape, the modal analysis was done in ModalVIEW R2 software. The better results was achieved in the

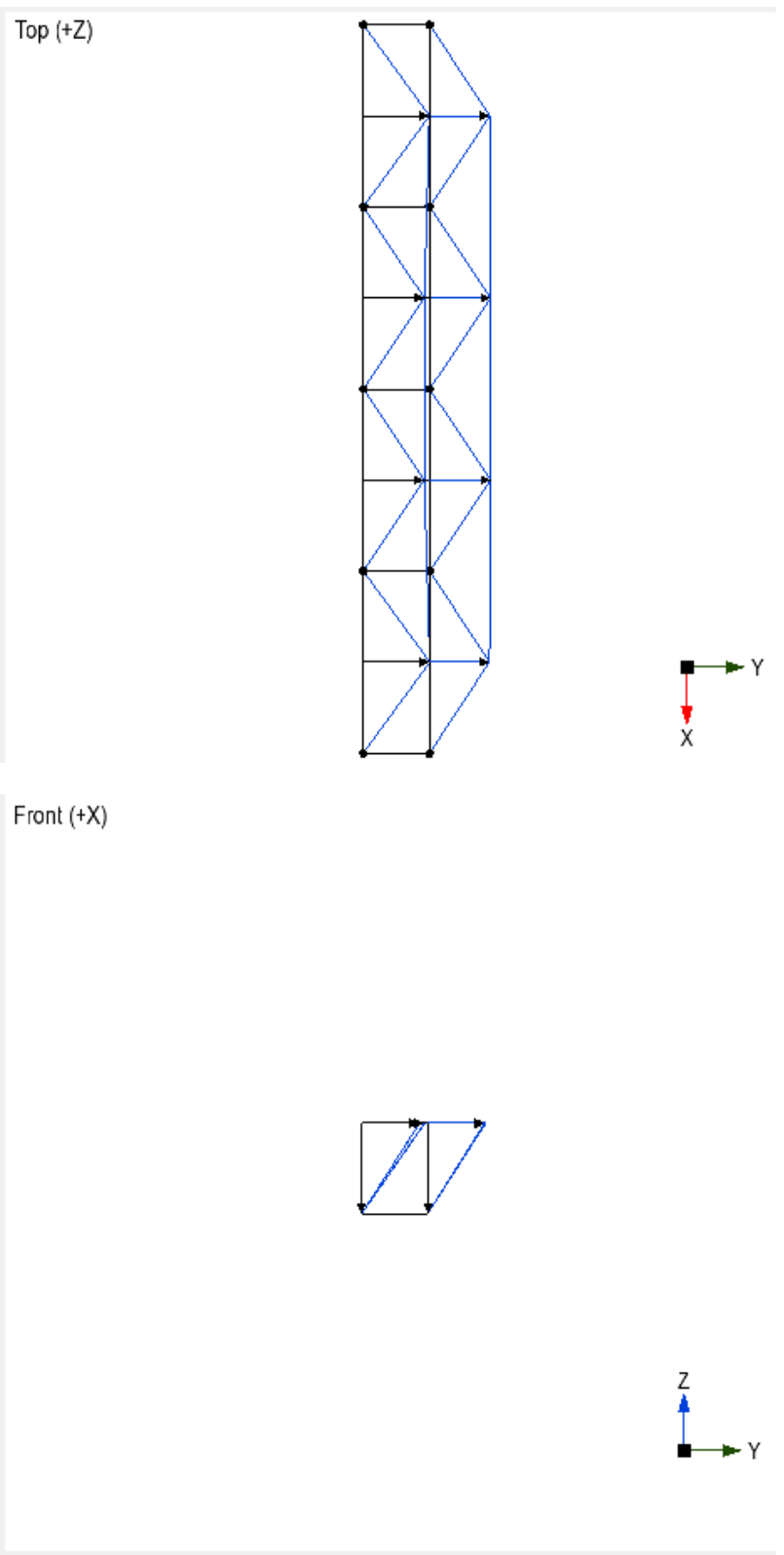

Figure 7. The first measured mode-shape: view (top) and cross-section (bottom).

FEM code, because ModalVIEW R2 software used many times less elements. But generally, the measured mode-shape (Figure 7) is comparable to the calculated one. The measured frequency was approximately $9.35 \mathrm{~Hz}$. The frequency is also in good conformity.

The comparison of another natural frequencies from the measurements and the numerical analysis is in Figure 8. The first two mode-shapes and the fourth represent global mode-shapes. The third mode-shape is represented as vibration of diagonal members, so it is local mode-shape. The fifth and higher mode-shapes are also local modes. 


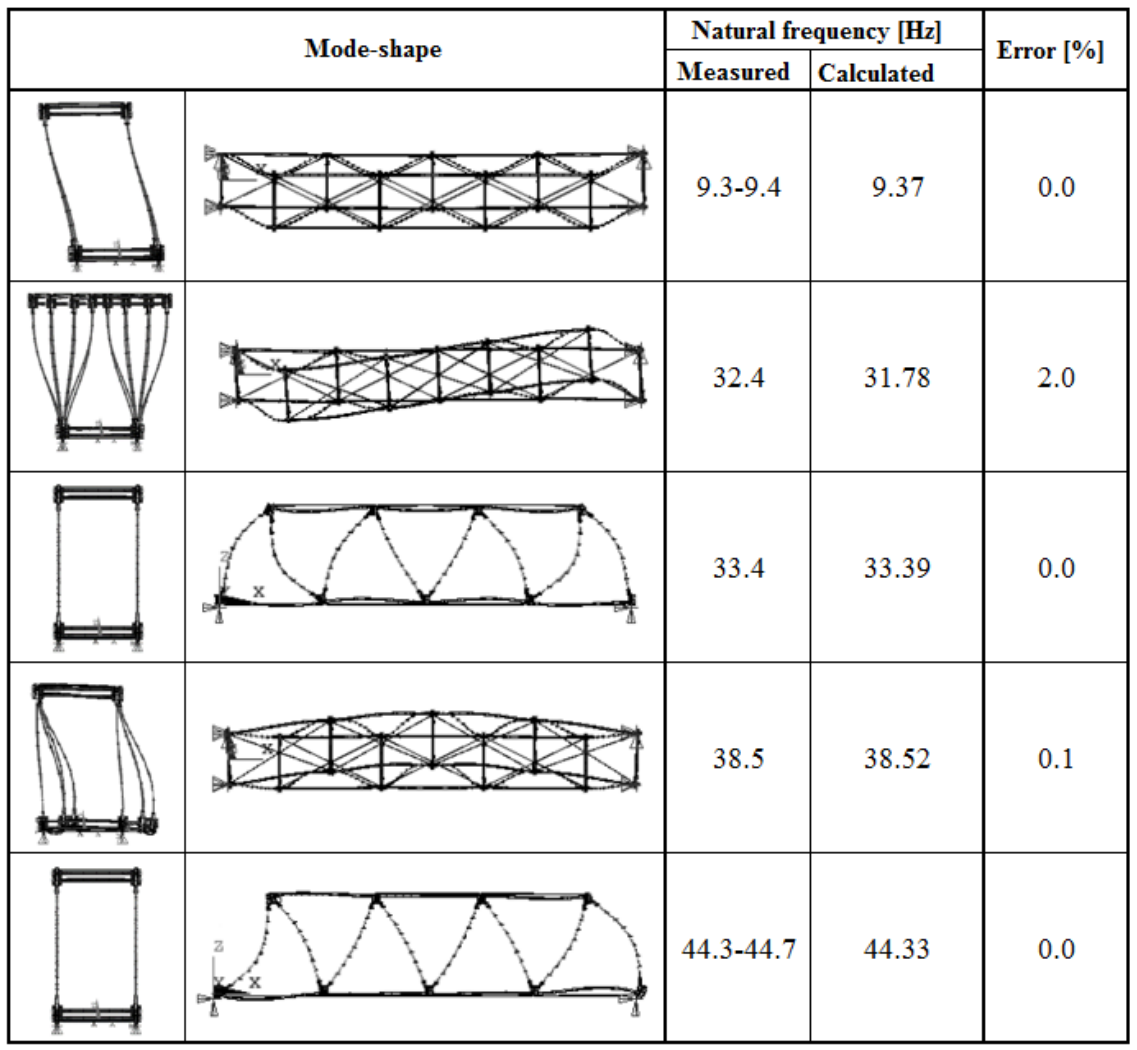

FigurE 8. Comparison of measured and calculated frequencies.

\section{SUMMARY AND CONCLUSIONS}

The laboratory investigation was utilized to test the numerical model. After mentioned revisions in the numerical model, the obtained results were satisfactory. The compared mass was equalled. The measured and calculated natural frequencies showed only small inaccuracies. The mode-shapes from the numerical model and the measurements gave us comparable outcomes. The tuned numerical model can be used for another calculations and measurements to detect local damages in joints.

\section{ACKNOWLEDGEMENTS}

This paper was supported by the Slovak Research and Development Agency (SRDA), i.e. a grant from research program No. APVV-0236-12; it was also created with the support of the Ministry of Education, Science, Research and Sport of the Slovak Republic within the Research and Development Operational Program for the project University Science Park of STU Bratislava, ITMS 26240220084. It was also supported by grant from research program Young researcher 2017.

\section{REFERENCES}

[1] American Society of Civil Engineers. The 2017 infrastructure report card. https://www.infrastructurereportcard.org/ wp-content/uploads/2016/10/ 2017-Infrastructure-Report-Card.pdf

[2] Z. Orban. Increasing the reliability of the assessment iof masonry archbridges by non-destructive testing.
Pollack Periodica 1(3):45-56, 2006. DOI:10.1556/Pollack.1.2006.3.4

[3] S. C. Siriwardane. Vibration measurement-based simple technique for damage detection of truss bridges: A case study. Case Stud Eng Fail Anal 4:50-58, 2015. DOI:10.1016/j.csefa.2015.08.001

[4] K.-C. Chang, C.-W. Kim. Modal-parameter identification and vibration-based damage detection of a damaged steel truss bridge. Eng Struct 122:156-173, 2016. DOI:10.1016/j.engstruct.2016.04.057

[5] J. Li, H. Hao. Health monitoring of joint conditions in steel truss bridges with relative displacement sensors. Measurement 88:360-371, 2016. DOI:10.1016/j.measurement.2015.12.009.

[6] A. Bayrakattar, A. C. Altunisik, T. Turker. Structural health assessment and restoration procedure of an old riveted steel arch bridge. Soil Dyn Earthquake Eng 83:148-161, 2016. DOI:10.1016/j.measurement.2015.12.009

[7] M. Sokol, M. Venglar. Increasing the reliability of the assessment iof masonry archbridges by non-destructive testing. Pollack Periodica 12(3), 2017. [in press].

[8] J. S. Wilson. Test and measurement. First printing. Newnes/Elsevier, Burlington, Mass, 2009.

[9] B. H. Thacker, S. W. Doebling, F. M. Hemez, et al. Concepts of model verification and validation. Technical report, 2004. [LA-14167-MS], https: //www.osti.gov/scitech/servlets/purl/835920 